\title{
A Reconfigurable UWB Bandpass Filters with Embedded Multi-Mode Resonators
}

\author{
Eman Gamal Ouf1,2, Ashraf S. Mohra3 ${ }^{3}$ Esmat Abdel-Fattah Abdallah', Hadia Elhennawy² \\ ${ }^{1}$ Electronics Research Institute, Giza, Egypt \\ ${ }^{2}$ Faculty of Engineering, Ain Shams University, Cairo, Egypt \\ ${ }^{3}$ Benha Faculty of Engineering, Benha University, Benha, Egypt \\ Email: emanouf@eri.sci.eg, amohra@bhit.bu.edu.eg, esmataa2@hotmail.com, helhennawy@ieee.org
}

How to cite this paper: Ouf, E.G., Mohra, A.S., Abdallah, E.A.-F. and Elhennawy, H. (2018) A Reconfigurable UWB Bandpass Filters with Embedded Multi-Mode Resonators. Open Journal of Antennas and Propagation, 6, 43-59.

https://doi.org/10.4236/ojapr.2018.63005

Received: August 16, 2018

Accepted: September 16, 2018

Published: September 19, 2018

Copyright (C) 2018 by authors and Scientific Research Publishing Inc. This work is licensed under the Creative Commons Attribution International License (CC BY 4.0).

http://creativecommons.org/licenses/by/4.0/

\begin{abstract}
The two proposed filters described here satisfy the Federal Communications Commission Ultra-wideband (FCC-UWB) specifications and also control the center frequency and bandwidth of the filters passband. These filters consist of two distinguishing parts, Electromagnetic bandgap (EBG)-embedded multiple-mode resonator (MMR) and interdigital coupled lines to realize high performance in the operation band with a compact size of $14.0 \mathrm{~mm} \times 10.1$ $\mathrm{mm}$. The main advantage of the two proposed filters is that three different bands are tuned. The 1st tuned band is from $3.5 \mathrm{GHz}$ to $11.4 \mathrm{GHz}$ for the first filter and from $3.1 \mathrm{GHz}$ to $11.6 \mathrm{GHz}$ for the second proposed filter, respectively. The 2nd tuned band is from $3.5 \mathrm{GHz}$ to $7.5 \mathrm{GHz}$ for the first filter and from $3.1 \mathrm{GHz}$ to $7.8 \mathrm{GHz}$ for the second proposed filter, respectively. While the $3 \mathrm{rd}$ tuned band of the first proposed filter is from $3.5 \mathrm{GHz}$ to $5.9 \mathrm{GHz}$ and from $3.1 \mathrm{GHz}$ to $5.8 \mathrm{GHz}$ for the second proposed filter. The bandwidth of the filters can be changed by increasing the length of the outer open circuited stubs which are controlled by using switching matrix equipment (mini circuit, replacement of PIN diodes). To validate the design theory, a reconfigurable UWB bandpass filters (BPFs) with EBG Embedded MMR are designed, fabricated and measured. Good agreement is found between simulated and measured results.
\end{abstract}

\section{Keywords}

UWB Bandpass Filter, EBG, MMR, Reconfigurable, Stubs

\section{Introduction}

The filters play an important role in effectively transmitting the desired signals in certain passband regions while attenuating all the undesired signals in the re- 
maining bandstop regions [1]. There are a lot of modern communication systems using the filters in their circuits, such as the embedded systems, mobile phone and wireless communication systems. It was necessary to explore alternative concepts because of the increasing demand for each of high-performance filters, circuit integration and reduced size [2]. The size of the filter can be reduced by reducing the resonator circuit with modifying its physical structures [3] [4]. Each of the conventional parallel coupled lines band-pass filter [5], U-shape resonators [6], open loops [7], and hairpin filters [8] helped in size reduction. The modern communication systems show a rapid evolution [9], that needs more size reduction of these resonators. The bandwidth and center frequency can be varied in tunable/reconfigurable band-pass filters.

Tunable bandwidth microwave filters are especially useful for the design of high-frequency multifunction receivers that support multiple information signals with different frequency bands.

Since that the UWB system has become one of the most favorable technologies for short-range low-power indoor wireless communications, and UWB BPF as one of the essential components of UWB systems $(3.1 \mathrm{GHz}-10.6 \mathrm{GHz})$ has obtained much attention in recent years. The reconfigurable UWB bandpass filter (BPF) will be provided, whereas the recent advances in modern wideband radar and wireless communication applications need high performance, reconfigurable, and compact RF subsystems. Therefore, much attention has been devoted for compact reconfigurable microwave devices. An important component for the multifunction receivers is the UWB BPF with passband from 3.1 to 10.6 GHz. So far, various techniques have been recently developed for UWB bandpass filters. Since 2005, various UWB bandpass filters have been designed and reported, including filters of composite lowpass and highpass structure [10] [11], short-circuited stub filters [12] [13], and multiple-mode resonator (MMR) structure filters [14] [15].

In this paper, we present two Reconfigurable Ultra-Wideband Bandpass Filters with Embedded Multi-Mode Resonator and Electromagnetic Bandgap (MMR-EBG). The proposed UWB BPFs consist of two distinguishing parts, EBG-embedded MMR and interdigital coupled lines to realize high performance in the operation band with a compact size of $14.0 \mathrm{~mm} \times 10.1 \mathrm{~mm}$. The MMR of the first proposed filter is formed by connected three open circuited stubs with two high impedance microstrip lines in center, but the MMR of the second proposed filter is formed by connected five open circuited stubs with four high impedance microstrip lines in center. The topology of a periodic structure with shunt capacitive loading is called electromagnetic bandgap (EBG) structures [16] [17]. The main advantage of the two proposed filters is introducing three different bands that can be tuned. The three different tuned bands for the first proposed filter are from 3.5 to $11.4 \mathrm{GHz}$, from $3.5 \mathrm{GHz}$ to $7.5 \mathrm{GHz}$ and from 3.5 $\mathrm{GHz}$ to $5.9 \mathrm{GHz}$, while the tuned bands for the second proposed filters are from 3.1 $\mathrm{GHz}$ to $11.6 \mathrm{GHz}$, from $3.1 \mathrm{GHz}$ to $7.8 \mathrm{GHz}$ and from $3.1 \mathrm{GHz}$ to $5.8 \mathrm{GHz}$. 
The reconfigurability of the proposed filters was proven by means of open and short circuits in certain locations which is controlled by using mini-circuit switching matrix equipment (which is the replacement of PIN diodes).

The paper is organized as follows: Section 2 provides the analysis of the proposed filter, and Section 3 introduces the design of the proposed filter in terms of the shape of the filter, its dimensions and the simulation results. Section 4 introduces the fabrication and the measurement of the proposed filters together with simulated results. The conclusion is given in Section 5.

\section{Analysis of the Proposed Filter}

Based on article [15], the corresponding equivalent circuit for the proposed filter is as shown in Figure 1. It is composed of MMR and $J$-inverters that represent the two coupled lines. The MMR is composed of EBG line in the center with two high impedance lines at two sides.

\subsection{Analysis of the Input/Output Section}

The input/output section is composed of two coupled lines with high impedance line as shown in Figure 2.

\subsubsection{Analysis of the Two Coupled Line}

The $A B C D$ matrix for the coupled line can be expressed as [18]:

$$
M_{c}=\left[\begin{array}{cc}
\cos \theta_{1} & j Z_{o} \sin \theta_{1} \\
\frac{j \sin \theta_{1}}{Z_{o}} & \cos \theta_{1}
\end{array}\right]\left[\begin{array}{cc}
0 & \frac{-j}{J} \\
-j J & 0
\end{array}\right]\left[\begin{array}{cc}
\cos \theta_{1} & j Z_{o} \sin \theta_{1} \\
\frac{j \sin \theta 1}{Z_{o}} & \cos \theta_{1}
\end{array}\right]
$$

$Z_{o}$ and $\theta_{1}$ represent the characteristic impedance and the electrical length of the coupled line, respectively; while $J$ is the admittance inverter. The admittance

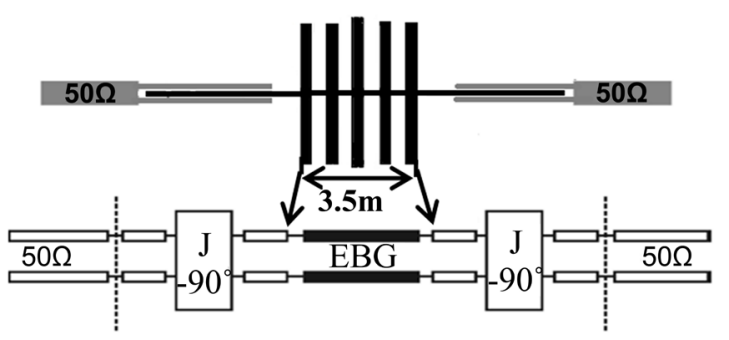

Figure 1. Schematic and equivalent transmission line network of the proposed UWB BPF on microstrip line topology [15].



(a)

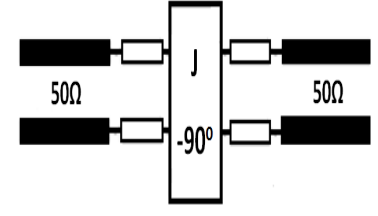

(b)

Figure 2. (a) Schematic and (b) equivalent transmission line network of the first part of the proposed filter. 
inverter $J$ in $A B C D$ matrix $M_{c}$ can be replaced by the even and odd mode characteristic impedances $\left(Z_{o e} \& Z_{o o}\right)$ of the coupled line [18]:

$$
\begin{gathered}
J Z_{o}+\frac{1}{J Z_{o}}=\frac{Z_{o e}+Z_{o o}}{Z_{o e}-Z_{o o}} \\
J Z_{o}^{2}=\frac{2}{Z_{o e}-Z_{o o}}
\end{gathered}
$$

Substituting by Equation (2), and Equation (3) into Equation (1); the $A B C D$ matrix of the coupled line becomes:

$$
M_{c}=\left[\begin{array}{cc}
\frac{Z_{o e}+Z_{o o}}{Z_{o e}-Z_{o o}} \cos \theta_{1} & \frac{-j}{2}\left[\frac{4 Z_{o e} Z_{o o}}{Z_{o e}-Z_{o o}} \frac{\cos ^{2} \theta_{1}}{\sin \theta_{1}}-\left(Z_{o e}-Z_{o 0}\right) \sin \theta_{1}\right. \\
j \frac{2}{Z_{o e}-Z_{o o}} \sin \theta_{1} & \frac{Z_{o e}+Z_{o o}}{Z_{o e}-Z_{o o}} \cos \theta_{1}
\end{array}\right]
$$

$Z_{o e}$ and $Z_{o o}$ can be calculated as in [2].

\subsubsection{High Impedance Line Analysis}

The $A B C D$ matrix of the high impedance line can be expressed as [18]:

$$
M_{H}=\left[\begin{array}{cc}
\cos \beta_{H} l_{H} & j Z_{H} \sin \beta_{H} l_{H} \\
\frac{j}{Z_{H}} \sin \beta_{H} l_{H} & \cos \beta_{H} l_{H}
\end{array}\right]
$$

where $Z_{H}$ is the highest line impedance, $\beta_{H}$ is the propagation constant and $I_{H}$ is the length of the high impedance line.

From Equation (4) \& Equation (5), the $A B C D$ matrix of the first part of the proposed filter is:

$$
M_{1}=M_{c} \times M_{H}
$$

Figure 3 shows the numerical results by using Mat-lab program version 2013 and simulated results by using CST MWS version 2014 of the input/output section. From Figure 3, it is clear that, both results are in good agreement.

\subsection{Analysis of the Multi-Mode Resonator Section}

The multi-mode resonator section can be considered as cascaded stepped impedance with high and low impedances as shown in Figure 4.

The $A B C D$ matrix of the second part can be expressed as follows [18]:

$$
\begin{gathered}
M_{\mathrm{I}}=\left[\begin{array}{cc}
\cos \beta_{1} l_{1} & j Z_{1} \sin \beta_{1} l_{1} \\
\frac{j}{Z_{c 1}} \sin \beta_{1} l_{1} & \cos \beta_{1} l_{1}
\end{array}\right] \\
M_{\mathrm{II}}=\left[\begin{array}{cc}
\cos \beta_{2} l_{2} & j Z_{1} \sin \beta_{2} l_{2} \\
\frac{j}{Z_{c 2}} \sin \beta_{2} l_{2} & \cos \beta_{2} l_{2}
\end{array}\right] \\
M_{\mathrm{III}}=M_{\mathrm{I}} \\
M_{\mathrm{IV}}=M_{\mathrm{II}}
\end{gathered}
$$




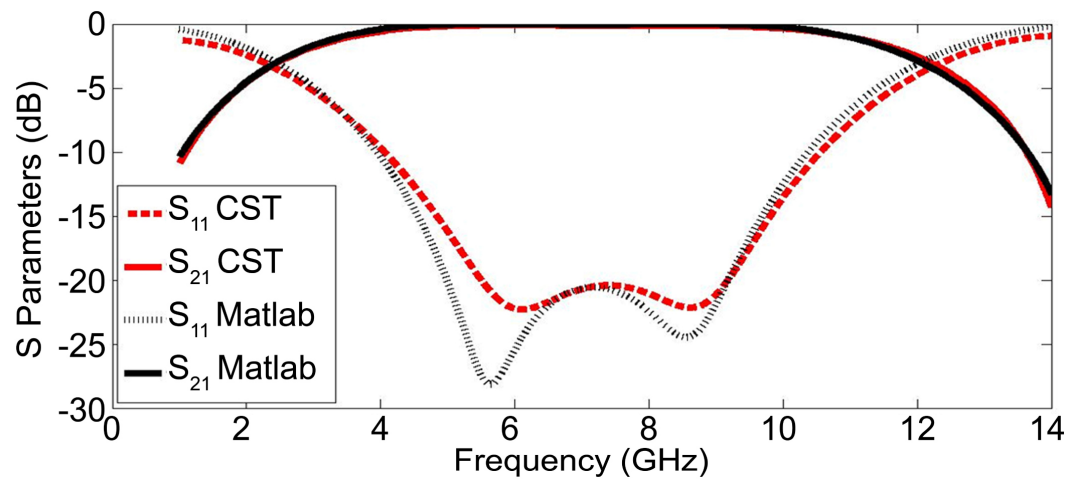

Figure 3. The numerical and simulated results for the input/output sections.



Figure 4. The multi-mode resonator section.

$$
\begin{gathered}
M_{\mathrm{V}}=\left[\begin{array}{cc}
\cos \beta_{5} l_{5} & j Z_{5} \sin \beta_{5} l_{5} \\
\frac{j}{Z_{c 5}} \sin \beta_{5} l_{5} & \cos \beta_{5} l_{5}
\end{array}\right] \\
M_{\mathrm{VI}}=M_{\mathrm{II}}=M_{\mathrm{IV}} \\
M_{\mathrm{VII}}=M_{\mathrm{III}}=M_{\mathrm{I}} \\
M_{\mathrm{VIII}}=M_{\mathrm{II}}=M_{\mathrm{IV}}=M_{\mathrm{VI}} \\
M_{\mathrm{IX}}=M_{\mathrm{I}}=M_{\mathrm{III}}=M_{\mathrm{VII}}
\end{gathered}
$$

From Equation (7) to Equation (15), the $A B C D$ matrix of the second part of the proposed filter is:

$$
M_{2}=M_{\mathrm{I}} \times M_{\mathrm{II}} \times \cdots \times M_{\mathrm{IX}}
$$

The characteristic impedance and propagation constant of each section can be calculated as in [2].

Figure 5 shows the numerical results by using Mat-lab program version 2013 and simulated results by using CST MWS version 2014 of the Multi-mode resonator section. From Figure 5, it is clear that, both results are in good agreement.

Therefore, from the above discussion, it is clear that the total $A B C D$ matrix of the proposed filter can be expressed as:

$$
\left[\begin{array}{ll}
A & B \\
C & D
\end{array}\right]=M_{1} \times M_{2} \times M_{1}
$$

The equations for computing the reflection and transmission coefficients from 




Figure 5. The numerical and simulated results for the Multi-mode resonator section.

the previous set of $A B C D$-parameter values of the proposed filter can be written as follows [18]:

$$
\begin{aligned}
& S_{11}=\frac{A+\frac{B}{Z_{0}}-c Z_{0}-D}{A+\frac{B}{Z_{0}}+c Z_{0}+D} \\
& S_{21}=\frac{2}{A+\frac{B}{Z_{0}}+c Z_{0}+D}
\end{aligned}
$$

Figure 6 shows the numerical results by using Mat-lab program and simulated results by using CST MWS of the proposed filter. Regarding $S_{11}$, there is frequency shift about $0.6 \mathrm{GHz}$ between the numerical and simulated results in the first resonant frequency. This may be attributed to the different method of analysis used in the CST and Mat-lab program, while this shift decreases with the second and third resonant frequency as illustrated in Figure 6. The $S_{21}$ shows very good agreement between the simulated and the numerical results especially in the band of operation from $3.1 \mathrm{GHz}$ to $11.6 \mathrm{GHz}$. Finally, from Figure 6, one can observe that both results are in good agreement.

\section{Filter Design}

The proposed filter is designed based on the example described in Ref. [19] but with a new contribution which is the controllable tunable bandwidth. This will be achieved by modifying the length of the outer open circuited stubs using diode switching matrix tools (instead of using PIN diodes). In this work, the proposed UWB-BPF consists of two parts, EBG-embedded MMR and interdigital coupled lines. The MMR is formed by connected series of open circuited stubs coupled with high impedance microstrip lines in center.

Three shapes of the proposed filter are presented, the first one is UWB BPF with MMR formed by three open circuited stubs mutually coupled with two high impedance microstrip lines in center, the second one is MMR formed by five open circuited stubs mutually coupled with four high impedance microstrip lines in center, and third one as same as the second one but with different length of each open circuited stubs. 


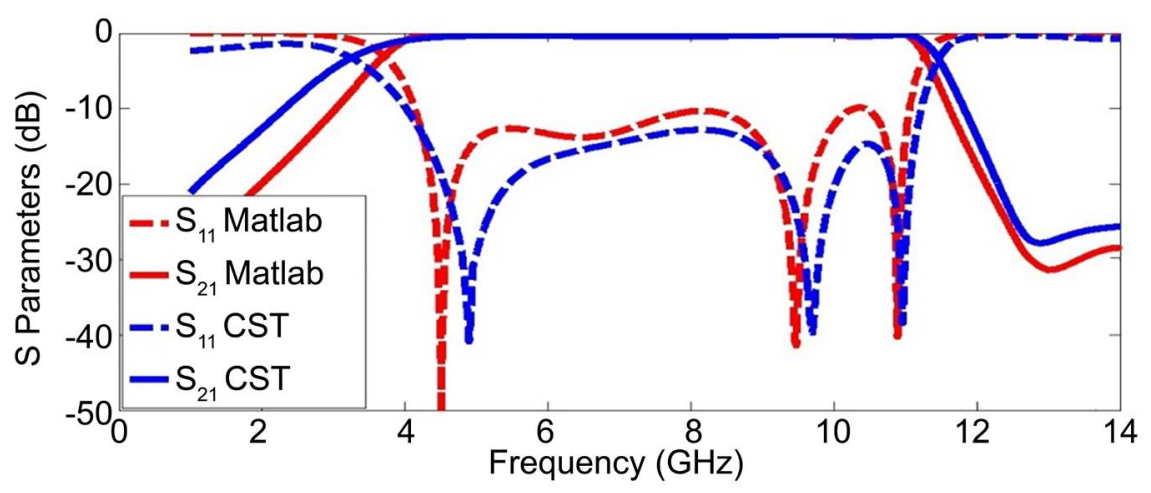

Figure 6. The numerical and simulated results of the proposed filter.

\subsection{First Proposed Filter Design}

The first proposed design with its optimized dimensions is shown in Figure 7. The overall dimension of the proposed filter is $14.0 \mathrm{~mm} \times 10.1 \mathrm{~mm}$. The filter operating bandwidth will be controlled by adjusting the length of the outer open circuited stubs $\left(\mathrm{W}_{\mathrm{L}}\right)$. As $\mathrm{W}_{\mathrm{L}}$ increases the bandwidth of the filter decreases as shown in Table 1 . The length $\mathrm{W}_{\mathrm{L}}$ is modified by using diodes switching matrix equipment where the character $\mathrm{D}$ refers to the diode and the different diodes states are described as follow:

1) When all the eight diodes $\left(D_{1}, D_{2}, D_{3}, D_{4}, D_{5}, D_{6}, D_{7}\right.$, and $\left.D_{8}\right)$ are in off state, the length $\mathrm{W}_{\mathrm{L}}$ will be equal to $4.9 \mathrm{~mm}$, so the bandwidth of the filter will be 7.9 GHz with band extends from $3.5 \mathrm{GHz}$ to $11.4 \mathrm{GHz}$.

2) When $D_{1}, D_{2}, D_{3}$, and $D_{4}$ are in on state; while $D_{5}, D_{6}, D_{7}$, and $D_{8}$ are in off state, the length $\mathrm{W}_{\mathrm{L}}$ will be equal to $7.5 \mathrm{~mm}$, so the bandwidth of the filter will be $4 \mathrm{GHz}$ with band extends from $3.5 \mathrm{GHz}$ to $7.5 \mathrm{GHz}$.

3) When all diodes $\left(D_{1}, D_{2}, D_{3}, D_{4}, D_{5}, D_{6}, D_{7}\right.$, and $\left.D_{8}\right)$ are on, the length $W_{L}$ will be equal to $10.1 \mathrm{~mm}$, so the bandwidth of the filter will be $2.4 \mathrm{GHz}$ with band extends from $3.5 \mathrm{GHz}$ to $5.9 \mathrm{GHz}$.

From the above discussion, the length $\mathrm{W}_{\mathrm{L}}$ can be modified to control the filter operating bandwidth. The above cases are summarized in Table 1 .

Figure 8 shows the simulated results of the proposed filter with different lengths of the outer open circuited stubs $\left(\mathrm{W}_{\mathrm{L}}\right)$ by using readymade software package (CST MWS version 2014). It is clear that the $3 \mathrm{~dB}$ bandwidth of the bandpass filter varies according to $\mathrm{W}_{\mathrm{L}}$, and thus there are three tuned bands with the three different lengths $\left(\mathrm{W}_{\mathrm{L}}\right)$.

\subsection{The Second Proposed Filter Design}

The second proposed design has five open circuited stubs mutually connected with four high impedance microstrip lines in middle as given in Figure 9. The overall dimension of the proposed filter is the same as the overall dimension of the first proposed filter $(14.0 \mathrm{~mm} \times 10.1 \mathrm{~mm})$ and the design procedure of the second proposed filter is the same as in first shape, but the passband starts from $3.1 \mathrm{GHz}$ instead of $3.5 \mathrm{GHz}$ and so the bandwidth is changed also. These differences 
Table 1. The $S$ parameters against $\left(\mathrm{W}_{\mathrm{L}}\right)$ for the first proposed filter.

\begin{tabular}{cccccc}
\hline \multirow{2}{*}{$\begin{array}{c}\mathrm{W}_{\mathrm{L}} \\
(\mathrm{mm})\end{array}$} & $\begin{array}{c}-3 \mathrm{~dB} \text { frequency } \\
\text { band }(\mathrm{GHz})\end{array}$ & \multicolumn{2}{c}{$\begin{array}{c}\text { Minimum and maximum values of } S \\
\text { parameters in passband }(\mathrm{dB})\end{array}$} & \multicolumn{2}{c}{$\begin{array}{r}\text { Roll off of passband and stop } \\
\text { band }(\mathrm{dB} / \mathrm{GHz})\end{array}$} \\
\cline { 3 - 6 } & & $S_{11}$ & $S_{21}$ & Pass band & Stop band \\
\hline 4.9 & $3.5-11.4$ & -3 to -45.4 & -0.1 to -3 & 12.47 & 11.8 \\
7.5 & $3.5-7.5$ & -3 to -63 & -0.12 to -3 & 35.3 & 7.09 \\
10.1 & $3.5-5.9$ & -3 to -42.6 & -0.12 to -3 & 36.7 & 8.5 \\
\hline
\end{tabular}

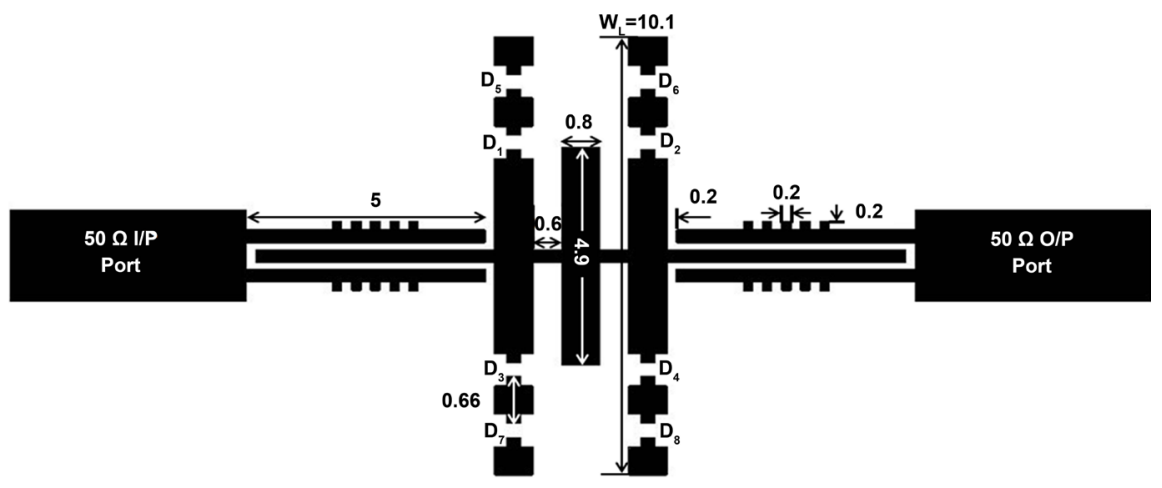

Figure 7. The proposed UWB BPF with three O.C. stubs and two high impedance microstrip lines (all dimensions in $\mathrm{mm}$ ).

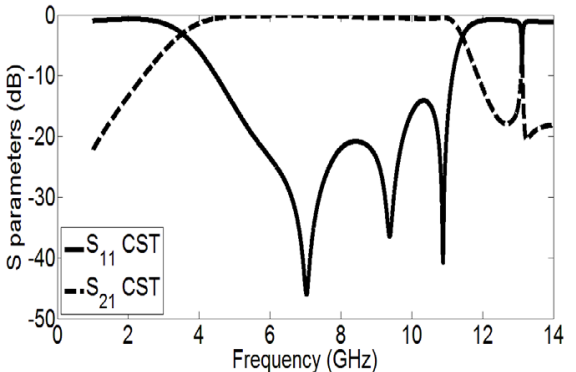

(a)

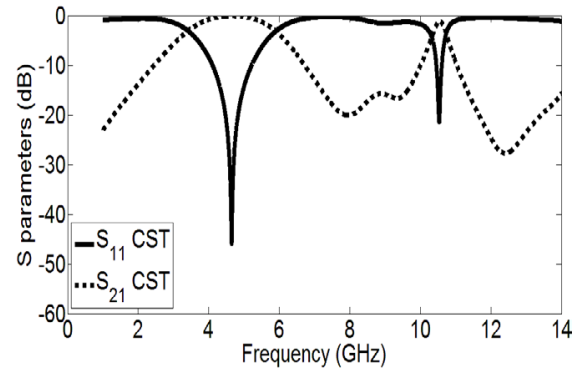

(c)

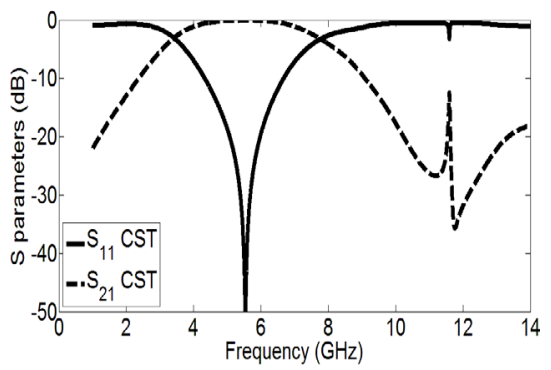

(b)

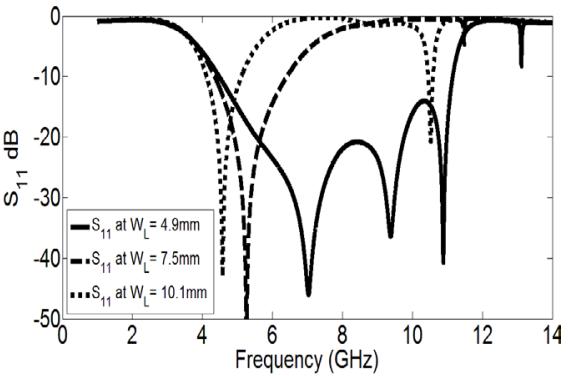

(d)

Figure 8. The simulated $1 S_{11} l$ and $1 S_{21} l$ using CST software package for different $\mathrm{W}_{\mathrm{L}}$ lengths, (a) $\mathrm{W}_{\mathrm{L}}=4.9 \mathrm{~mm}$; (b) $\mathrm{W}_{\mathrm{L}}=7.5 \mathrm{~mm}$; (c) $\mathrm{W}_{\mathrm{L}}=10.1 \mathrm{~mm}$; and (d) $I S_{11} 1$ for all values of $\mathrm{W}_{\mathrm{L}}$.

are given in Table 2. Figure 10 shows the simulated results of the second proposed filter design, there are three bands with different lengths of the outer open circuited stubs $\left(\mathrm{W}_{\mathrm{L}}=4.9,7.5,10.1 \mathrm{~mm}\right)$ by using CST. It should be noted that 
Table 2. The $S$ parameters against $\left(\mathrm{W}_{\mathrm{L}}\right)$ for the second proposed filter.

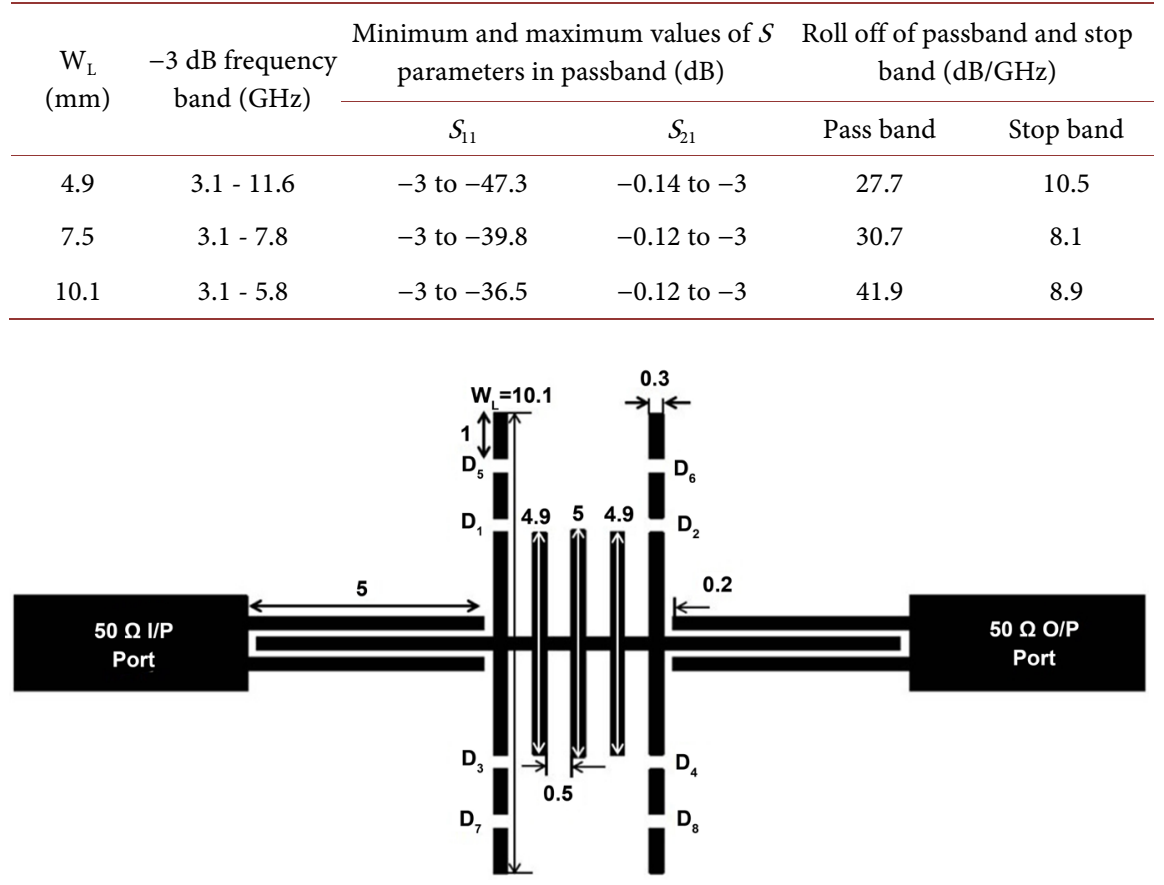

Figure 9. The proposed UWB BPF with five O.C. stubs and four high impedance microstrip lines (all dimensions in $\mathrm{mm}$ ).



(a)

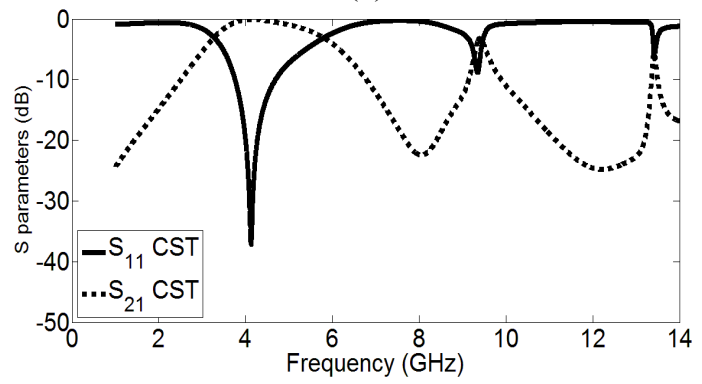

(c)

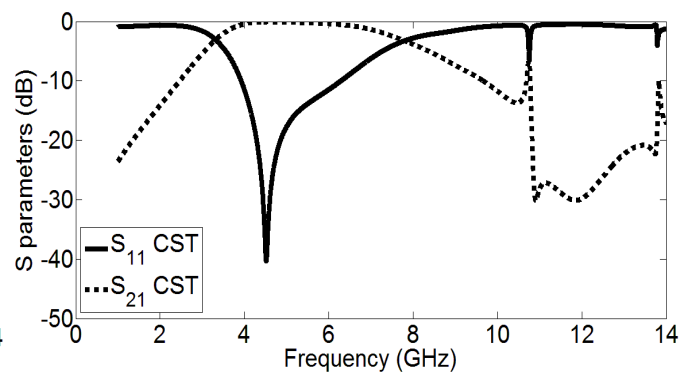

(b)

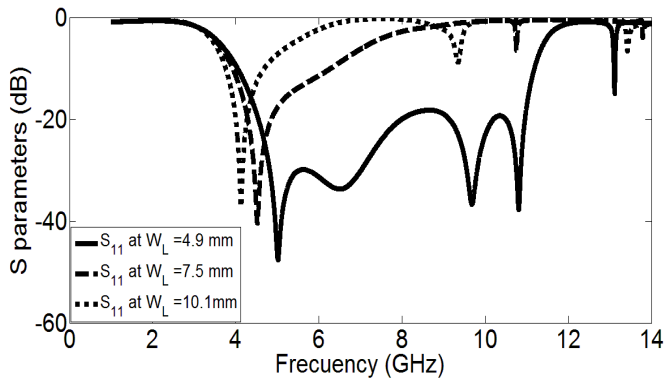

(d)

Figure 10. The simulated $I S_{11} l$ and $I S_{21} l$ using CST software package for different $\mathrm{W}_{\mathrm{L}}$ lengths, (a) $\mathrm{W}_{\mathrm{L}}=4.9$ $\mathrm{mm}$; (b) $\mathrm{W}_{\mathrm{L}}=7.5 \mathrm{~mm}$; (c) $\mathrm{W}_{\mathrm{L}}=10.1 \mathrm{~mm}$; and (d) $l S_{11} l$ for all values of $\mathrm{W}_{\mathrm{L}}$.

the roll off of the second filter in the passband is better than the first one, and the bandwidth increased to $8.5 \mathrm{GHz}$ instead of $7.9 \mathrm{GHz}$ as shown in Table 2 . Also the first resonance of the second filter occurs at $5 \mathrm{GHz}$ instead of $6.9 \mathrm{GHz}$ 
for the first filter as in Figure 11, so the performance of the second filter is better than the first one especially for the case of $\mathrm{W}_{\mathrm{L}}=4.9 \mathrm{~mm}$.

\subsection{The Modification of the Second Proposed Filter}

From the second proposed filter performance, it is noticed that the selectivity and the out of band rejection are bad, so it has been modified to improve them. An optimization procedure was carried out and the length $\mathrm{L}_{3}$ was changed from $5 \mathrm{~mm}$ to $4 \mathrm{~mm}, \mathrm{~L}_{2}$ changed from $4.9 \mathrm{~mm}$ to $3.6 \mathrm{~mm}$, and $\mathrm{L}_{1}$ remains the same as shown in Figure 12.

The design procedure of the modified filter is the same as in the second proposed filter. Figure 13 shows the simulated results of the modified filter design, there are three bands with different lengths of the outer open circuited stubs $\left(\mathrm{W}_{\mathrm{L}}\right.$ $=4.9,7.5,10.1 \mathrm{~mm}$ ) by using CST.

It should be noticed that the selectivity is improved and the out of band rejection has become better ( $S_{21}$ improved by more than $20 \mathrm{~dB}$ from 11.6 to $14 \mathrm{GHz}$ ) for the case of $\mathrm{W}_{\mathrm{L}}=4.9 \mathrm{~mm}$ as in Figure 14, and as in Table 3 .

Our proposed designed filter is compared with similar filters as given in Table 4 , where we noticed that the proposed filters are distinguished from the other published filters due to smaller size and larger bandwidth. The proposed design achieves total area reduction of more than 50\% compared with [21], 70\% compared with [22], and 54\% compared with [23]. It also provides a wider operating bandwidth, achieving a 10.6\% increase in bandwidth compared with [20] [23], $18.6 \%$ compared with [21], and $1.2 \%$ compared with [22].

\section{Fabrication and Measurements}

The designed filters are fabricated using thin film technology and photolithographic technique on Rogers RO3006 (lossy) substrate with $\left(\varepsilon_{r}=6.15, \mathrm{~h}=1.52\right.$ $\mathrm{mm}$, and $\tan \delta=0.002$ ). The photos for the fabricated filters are shown in Figure 15. The connecting wires are soldered to the circuit, and then connecting the diode switch matrix tool (that replaces the PIN diode switch). The filters are

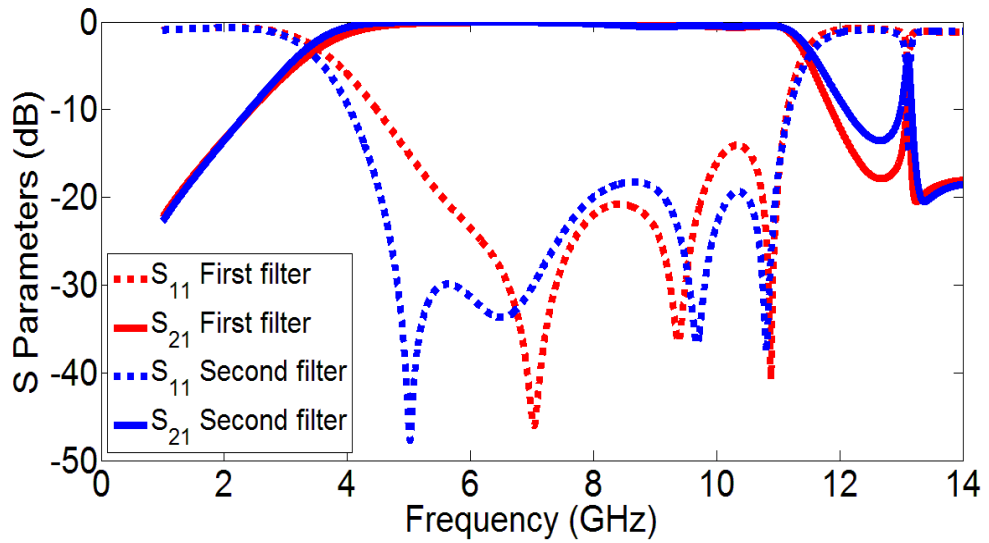

Figure 11. The simulated $I S_{11} l$ and $l S_{21} l$ using CST software package for the first and the second filters. 


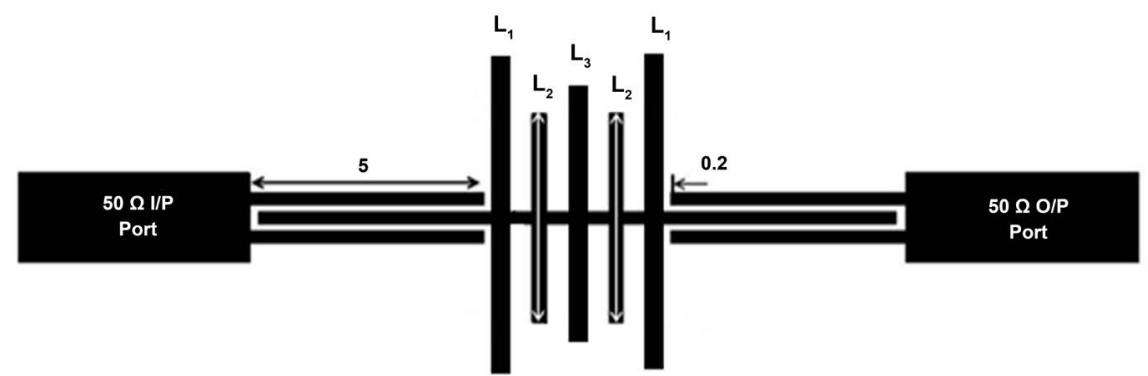

Figure 12. The modified UWB BPF with five O.C. stubs and four high impedance microstrip lines (all dimensions in $\mathrm{mm}$ ).

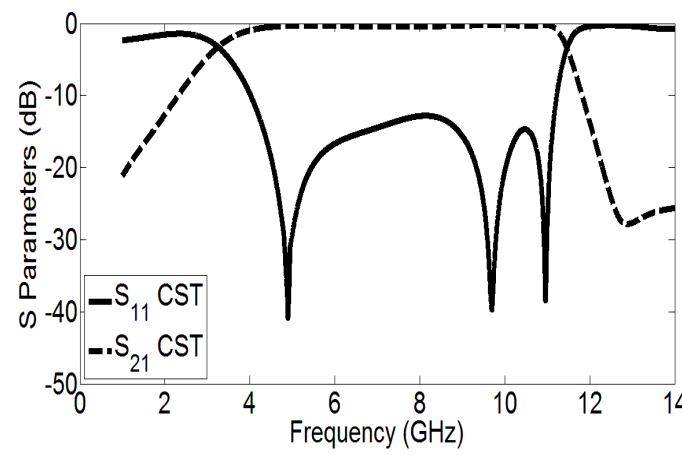

(a)

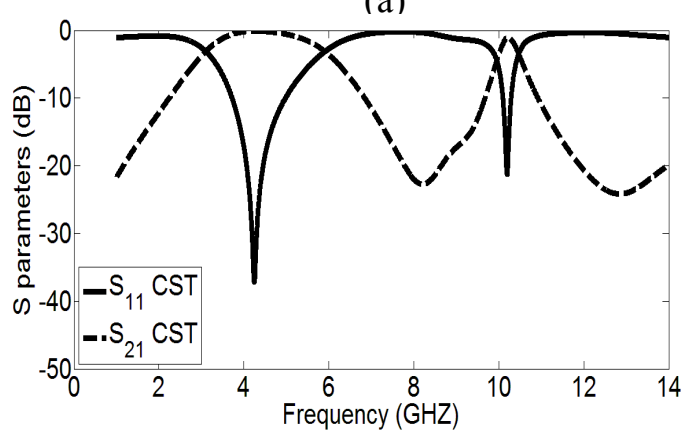

(c)

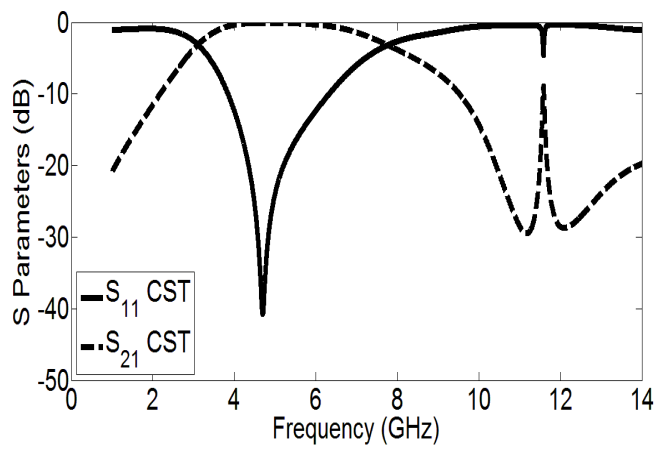

(b)

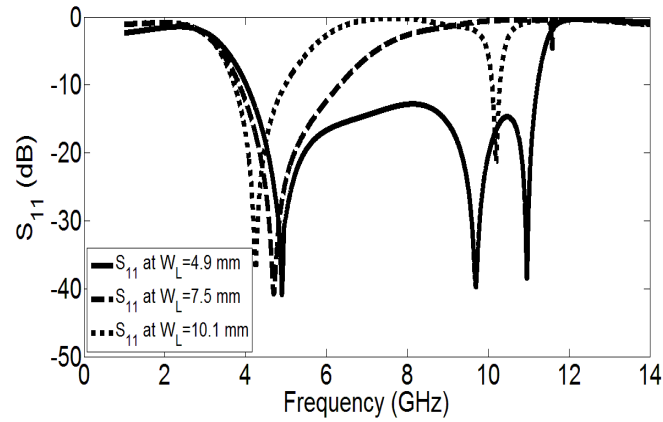

(d)

Figure 13. The simulated $I S_{11} l$ and $I S_{21} l$ for the modification of the second proposed filter design using CST software package for different $\mathrm{W}_{\mathrm{L}}$ lengths. (a) $\mathrm{W}_{\mathrm{L}}=4.9 \mathrm{~mm}$; (b) $\mathrm{W}_{\mathrm{L}}=7.5 \mathrm{~mm}$; (c) $\mathrm{W}_{\mathrm{L}}=10.1 \mathrm{~mm}$; and (d) $l S_{11} l$ for all $\mathrm{W}_{\mathrm{L}}$.

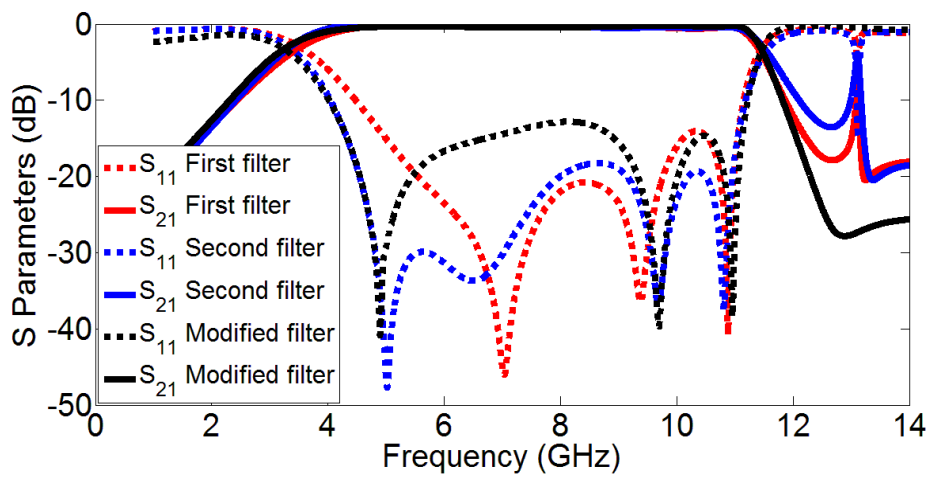

Figure 14. The simulated $l S_{11} l$ and $I S_{21} l$ using CST software package for the three shapes of filters. 
Table 3. The $S$ parameters against $\left(\mathrm{W}_{\mathrm{L}}\right)$ for the modified proposed filter.

\begin{tabular}{cccccc}
\hline & & \multicolumn{2}{c}{$\begin{array}{c}\text { Minimum and maximum values of } S \\
\mathrm{~W}_{\mathrm{L}}\end{array}$} & $\begin{array}{c}-3 \mathrm{~dB} \text { frequency } \\
\text { band }(\mathrm{GHz})\end{array}$ & \multicolumn{2}{c}{$\begin{array}{c}\text { Roll off of passband and } \\
\text { parameters in passband }(\mathrm{GHz})\end{array}$} & \multicolumn{2}{c}{ stop band $(\mathrm{dB} / \mathrm{GHz})$} \\
\cline { 3 - 6 } & & $S_{11}(\mathrm{~dB})$ & $S_{21}(\mathrm{~dB})$ & Pass band & Stop band \\
\hline 4.9 & 3.1 to 11.6 & -3 to -43.5 & -0.2 to -3 & 27.8 & 15.7 \\
7.5 & 3.1 to 7.8 & -3 to -39.2 & -0.1 to -3 & 25.9 & 8.4 \\
10.1 & 3.1 to 5.8 & -3 to -36.8 & -0.13 to -3 & 33.8 & 8.5 \\
\hline
\end{tabular}

Table 4. Comparison of the proposed filter with published UWB Bandpass filters.

\begin{tabular}{cccccc}
\hline Ref. & $\begin{array}{c}\text { Dielectric } \\
\text { constant }\left(\varepsilon_{r}\right)\end{array}$ & Height $(\mathrm{mm})$ & Size of filter & $\begin{array}{c}\text { Center } \\
\text { frequency } \\
\text { f0 }(\mathrm{GHz})\end{array}$ & $\begin{array}{c}\text { Passband } \\
(\mathrm{GHz})\end{array}$ \\
\hline $\begin{array}{c}\text { Ref. [20] } \\
\text { Ref. [21] }\end{array}$ & 10.8 & 0.635 & $23.98 \mathrm{~mm} \times 4.96 \mathrm{~mm}$ & 6.85 & $3.1-10.6$ \\
Ref. [22] & 3.38 & 0.508 & $20 \mathrm{~mm} \times 15 \mathrm{~mm}$ & 7.1 & $3.6-10.6$ \\
Ref. [23] & 2.65 & 1 & $30 \mathrm{~mm} \times 16 \mathrm{~mm}$ & 6.85 & $2.8-11.0$ \\
1st filter & 6.15 & 1.52 & $14.0 \mathrm{~mm} \times 10.1 \mathrm{~mm}$ & 7.45 & $3.5-11.4$ \\
Our work 2nd filter & 6.15 & 1.52 & $14.0 \mathrm{~mm} \times 10.1 \mathrm{~mm}$ & 7.35 & $3.1-11.6$ \\
modified & 6.15 & 1.52 & $14.0 \mathrm{~mm} \times 10.1 \mathrm{~mm}$ & 7.35 & $3.1-11.6$ \\
\hline
\end{tabular}

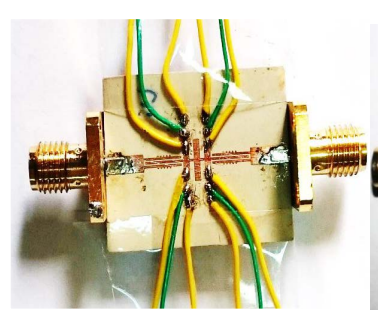

(a)

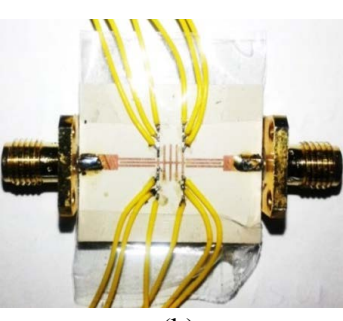

(b)

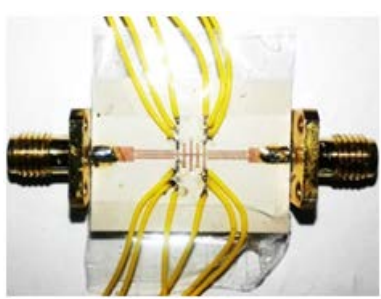

(c)

Figure 15. Photos for the fabricated filters, (a) First shape; (b) Second shape; (c) Third shape.

measured using the vector network analyzer (N9928A FieldFox Handheld Microwave Vector Network Analyzer, 26.5 GHz.).

Figures 16-18 show the measured and simulated results of the three structures. The measured results are consistent with the simulated ones. The measured $3 \mathrm{~dB}$ passband of the first proposed filter is between 3.5 to $11.4 \mathrm{GHz}$ in the 1st band, while in the second and third proposed filter is from $3.1 \mathrm{GHz}$ to 11.6 $\mathrm{GHz}$, from 3.5 to $7.5 \mathrm{GHz}$ in the 2nd band of the first filter, while in the second and third filter from $3.1 \mathrm{GHz}$ to $7.8 \mathrm{GHz}$, and from 3.5 to $5.9 \mathrm{GHz}$ in the $3 \mathrm{rd}$ band of the first filter, while in the second and third filter from $3.1 \mathrm{GHz}$ to 5.8 $\mathrm{GHz}$. All filters have compact sizes with dimensions $14.0 \mathrm{~mm} \times 10.1 \mathrm{~mm}$.

Figure 18(a) shows the measured and simulated $I S_{11} l$ and $I S_{21} l$ of the modified filter with five open circuit stubs with frequency range from $1 \mathrm{GHz}$ to $20 \mathrm{GHz}$ at $\mathrm{W}_{\mathrm{L}}=4.9 \mathrm{~mm}$. It should be noted that the frequency range is extented up to 20 


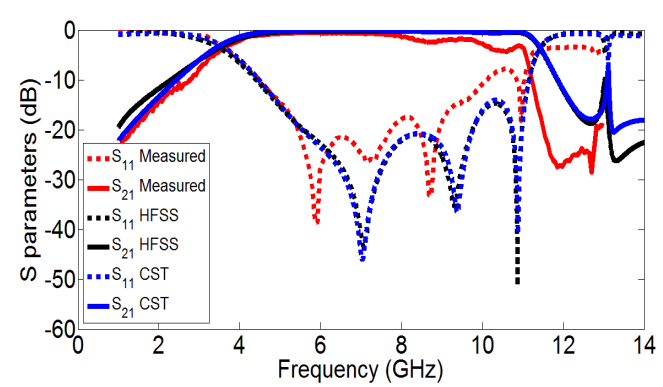

(a)

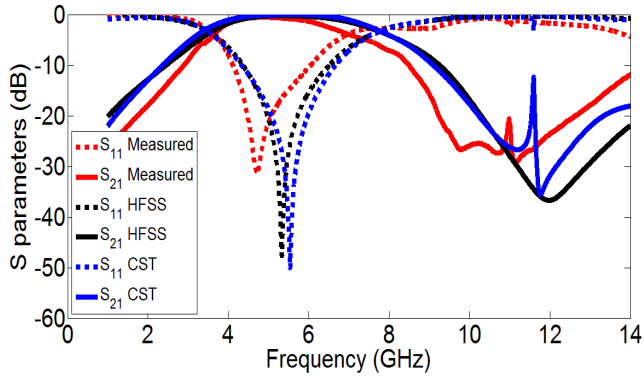

(b)



(c)

Figure 16. The simulated and measured $I S_{11} l$ and $I S_{21} l$ for the first filter shape for different $\mathrm{W}_{\mathrm{L}}$ lengths (a) $\mathrm{W}_{\mathrm{L}}=4.9 \mathrm{~mm}$; (b) $\mathrm{W}_{\mathrm{L}}=7.5 \mathrm{~mm}$; and (c) $\mathrm{W}_{\mathrm{L}}=10.1 \mathrm{~mm}$.

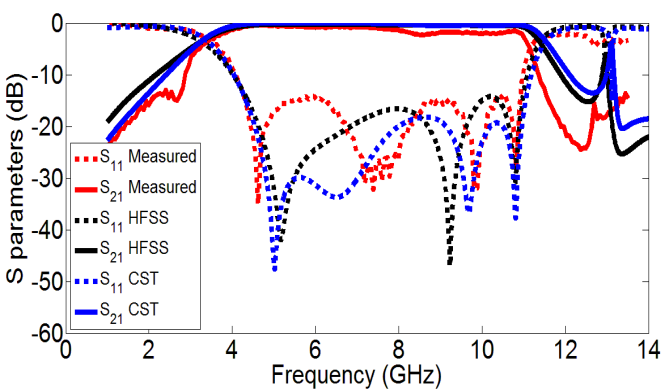

(a)



(b)

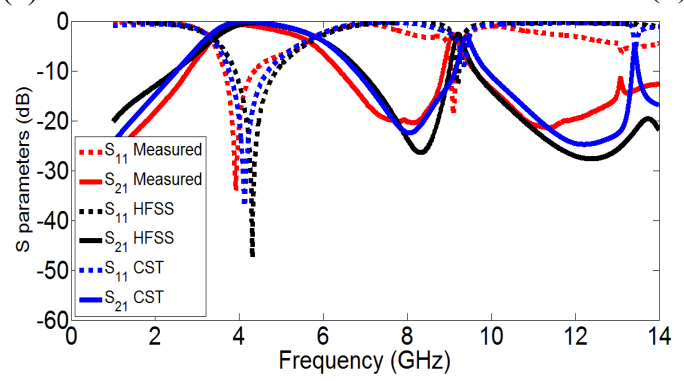

(c)

Figure 17. The simulated and measured $l S_{11} l$ and $l S_{21} l$ for the second filter shape for different $\mathrm{W}_{\mathrm{L}}$ lengths (a) $\mathrm{W}_{\mathrm{L}}=4.9 \mathrm{~mm}$; (b) $\mathrm{W}_{\mathrm{L}}=7.5 \mathrm{~mm}$; and (c) $\mathrm{W}_{\mathrm{L}}=10.1 \mathrm{~mm}$.

$\mathrm{GHz}$ in order to show that the out of band rejection has been improved due to the modifications that were carried out in the lengths of the open circuit stubs. HFSS software package was also used as another simulation tool to validate and verify the obtained performance of the proposed filters. Figure 19 shows the group delay variations for the three shapes of the proposed filters simulated by 


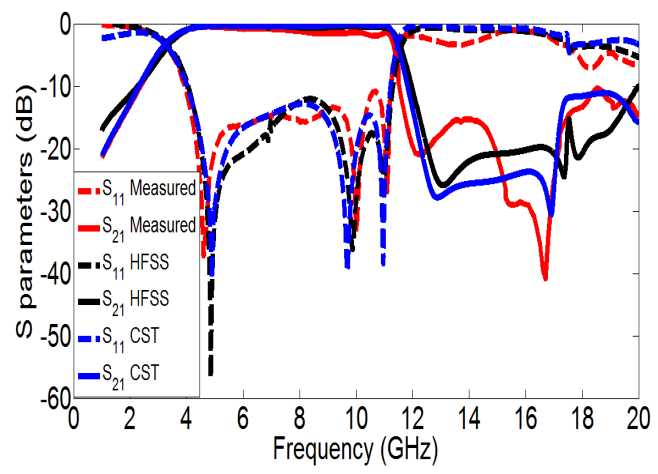

(a)

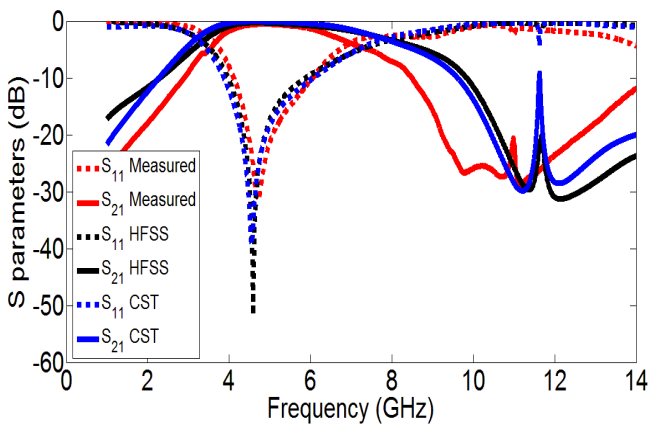

(c)

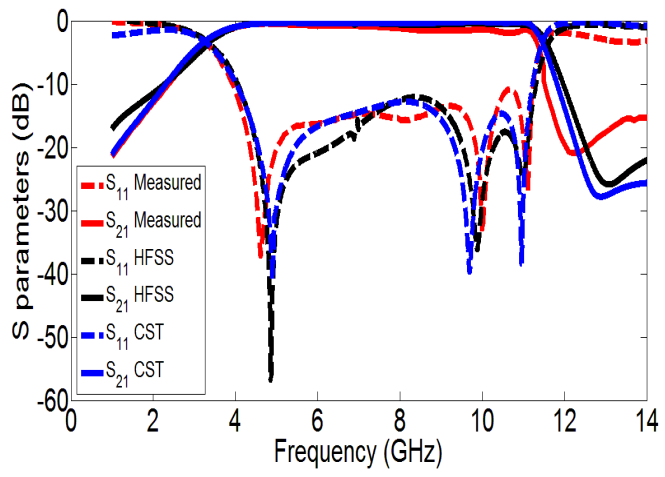

(b)

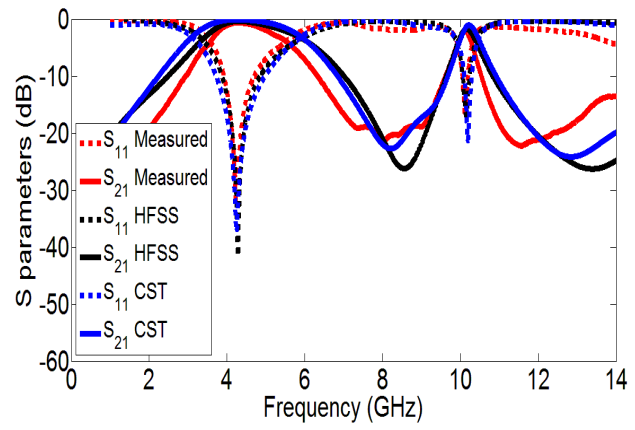

(d)

Figure 18. The simulated and measured $l S_{11} l$ and $l S_{21} l$ for the modification of the second proposed filter for different $\mathrm{W}_{\mathrm{L}}$ lengths (a) $\mathrm{W}_{\mathrm{L}}=4.9 \mathrm{~mm}$ (with frequency range from $1 \mathrm{GHz}$ to $20 \mathrm{GHz}$ ); (b) $\mathrm{W}_{\mathrm{L}}$ $=4.9 \mathrm{~mm}$; $(\mathrm{c}) \mathrm{W}_{\mathrm{L}}=7.5 \mathrm{~mm}$ and $(\mathrm{d}) \mathrm{W}_{\mathrm{L}}=10.1 \mathrm{~mm}$.

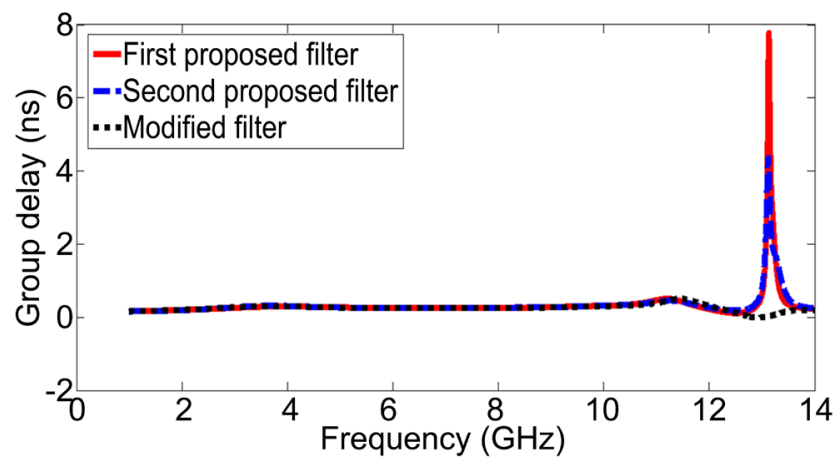

Figure 19. The group delay for the three shapes of the proposed filter.

the CST MWS software. It should be noted that the maximum variation of group delay within $1-14 \mathrm{GHz}$ is $0.4 \mathrm{~ns}$ for the modified filter, while the maximum variation of group delay for second proposed filter is $4.35 \mathrm{~ns}$, and for the first proposed filter is $7.68 \mathrm{~ns}$. As can be noted that the reported values for the modified proposed filter is lower than the other two proprosed filters and indicates a very low distortion that can be happened for the modified filter.

From the above figures, one can notice that:

1) There is a difference between the first, second, and third shape of the proposed filter in the frequency band and the center frequency as shown in Table 5, as well as differences in group delay and roll off behavior. 
Table 5. Comparison between the three shapes of the proposed filters.

\begin{tabular}{|c|c|c|c|c|c|c|c|}
\hline \multirow{2}{*}{$\begin{array}{c}\text { No. of } \\
\text { filter } \\
\text { shape at } \\
\mathrm{W}_{\mathrm{L}}=4.9 \\
\mathrm{~mm}\end{array}$} & \multirow{2}{*}{$\begin{array}{l}-3 \mathrm{~dB} \\
\text { frequency band } \\
\qquad(\mathrm{GHz})\end{array}$} & \multicolumn{2}{|c|}{$\begin{array}{c}\text { Minimum and maximum } \\
\text { values of } S \text { parameters in } \\
\text { passband }(\mathrm{GHz})\end{array}$} & \multicolumn{2}{|c|}{$\begin{array}{c}\text { Roll off of } \\
\text { passband and stop } \\
\text { band }(\mathrm{dB} / \mathrm{GHz})\end{array}$} & \multirow{2}{*}{$\begin{array}{l}\text { Impedance } \\
\text { matching } \\
(\mathrm{dB})\end{array}$} & \multirow{2}{*}{$\begin{array}{c}\text { Group delay } \\
\text { at } \\
(1-14 \mathrm{GHz}) \\
\text { (ns) }\end{array}$} \\
\hline & & $S_{11}(\mathrm{~dB})$ & $S_{21}(\mathrm{~dB})$ & $\begin{array}{l}\text { Pass } \\
\text { band }\end{array}$ & Stop band & & \\
\hline Shape 1 & 3.5 to & -3 to -45.4 & -01 to & 12.47 & 11.8 & 5 & 0.15 \\
\hline Shape 2 & 3.1 to 11.6 & -3 to -47.3 & -0.14 to -3 & 27.7 & 10.5 & $<-20$ & $0.15-4.35$ \\
\hline Shape 3 & 3.1 to 11.6 & -3 to -43.5 & -0.2 to -3 & 27.8 & 15.7 & $<-15$ & $0.15-0.4$ \\
\hline
\end{tabular}

2) The insertion loss within the pass band of the two shapes is the same.

3) The fabrication of the second and third shapes is more difficult than the first shape.

4) The slope of the insertion loss of the third shape is sharper than the first and second shape.

\section{Conclusion}

Reconfigurable Ultra-Wideband Bandpass Filters with EBG Embedded Multi-Mode Resonator have been designed, simulated, and fabricated. Two packages of software were used, namely CST MWS 2014 and 3D EM commercial software HFSS version 13.0 to design and simulate the filters. The simulated and measured results are comparable. The measured results were characterized using a N9928A FieldFox Handheld Microwave Vector Network Analyzer, 26.5 GHz. Small size and three different frequency bands add some advantages to these filters. By adjusting the length of the outer open circuit stubs, the center frequency and the $3 \mathrm{~dB}$ frequency band can be easily adjusted. The final size of these filters is $14.0 \mathrm{~mm} \times 10.1 \mathrm{~mm}$, which is suitable for modern ultra-wide band wireless communication systems. According to The FCC regulations, the proposed filters in all their structures satisfy the definitions of the UWB filters whether according to the first definition of FCC which is $3.1-10.6 \mathrm{GHz}$ bandwidth requirements or according the second definition which is $500 \mathrm{MHz}$ bandwidth requirements. So, the proposed filter can be used in communication systems with UWB application [24].

\section{Conflicts of Interest}

The authors declare no conflicts of interest regarding the publication of this paper.

\section{References}

[1] Mattaei, G., Young, L. and Jones, E.M.T. (1980) Microwave Filters, Impedance-Matching Networks, and Coupling Structures. Artech House, Norwood, MA.

[2] Hong, J.-S. and Lancaster, M.J. (2011) Microstrip Filters for RF/Microwave Applications. Wiley-Interscience, Hoboken, NJ. https://doi.org/10.1002/9780470937297 
[3] Shum, K.M., Mo, T.T., Xue, Q. and Chan, C.H. (2005) A Compact Bandpass Filter with Two Tuning Transmission Zeros Using a CMRC Resonator. IEEE Transactions on Microwave Theory and Techniques, 53, 895-900. https://doi.org/10.1109/TMTT.2004.842492

[4] Saadi, A.A., Mustapha, C.E.Y., Abdelhalim, S., Abdelkader, T., Rachida, T. and Mohand, T.B. (2016) Compact UWB Bandpass Filter Based on Simple Radial Stub Resonator Structure. Microwave and Optical Technology Letters, 58, 1707-1710. https://doi.org/10.1002/mop.29884

[5] Wu, Y., Zhou, S., Zhang, W., Liao, M. and Liu, Y. (2014) Coupled-Line Dual-Band Bandpass Filter with Compact Structure and Wide Stopband. Electronics Letters, 50, 187-189. https://doi.org/10.1049/el.2013.3791

[6] Pan, Z. and Wang, J. (2008) Design of the UWB Bandpass Filter by Coupled Microstrip Lines with U-Shaped Defected Ground Structure. 2008 International Conference on Microwave and Millimeter Wave Technology, Nanjing, China, 21-24 April 2008, 329-332.

[7] Hong, J.-S. and Lancaster, M.J. (1996) Coupling of Microstrip Square Open Loop Resonators for Cross-Coupled Planar Microwave Filters. IEEE Transactions on Microwave Theory and Techniques, 44, 2099-2109. https://doi.org/10.1109/22.543968

[8] Wang, H. and Chu, Q.-X. (2010) A Narrow-Band Hairpin-Comb Two Pole Filter with Source-Load Coupling. IEEE Transactions on Microwave Theory and Techniques, 20, 372-374. https://doi.org/10.1109/LMWC.2010.2049426

[9] Chen, C.-F., Huang, T.-Y. and Wu, R.-B. (2006) Novel Compact Net-Type Resonators and Their Applications to Microstrip Bandpass Filters. IEEE Transactions on Microwave Theory and Techniques, 54, 755-762.

[10] Hsu, C.L., Hsu, F.C. and Kuo, J.T. (2005) Microstrip Bandpass Filters for U1tra-Wideband (UWB) Wireless Communications. IEEE MTT-S International Microwave Symposium Digest, Long Beach, CA, USA, 17 June 2005, 679-682.

[11] Men Zel, W., Tito, M.S.R. and Zhu, L. (2005) Low-Loss Ultra-Wide Band (UWB) Filters Using Suspended Strip Line. Proceedings of AMPC Conference 2005, Suzhou, 4-7 December 2005, 2148-2151.

[12] Hong, J.S. and Shaman, H. (2005) An Optimum Ultra-Wide-Band Microstrip Filter. Microwave and Optical Technology Letters, 47, 230-233. https://doi.org/10.1002/mop.21133

[13] Li, X. and Ji, X. (2014) Novel Compact UWB Bandpass Filters Design with Cross-Coupling Between Short-Circuited Stubs. IEEE Microwave Theory and Wireless Component Letters, 2, 23-25. https://doi.org/10.1109/LMWC.2013.2287231

[14] Zhu, L., Sun, S. and Menzel, W. (2005) Ultra-Wideband (UWB) Bandpass Filters Using Multiple-Mode Resonator. IEEE Microwave Theory and Wireless Component Letters, 15, 796-798.

[15] Wong, S.W. and Zhu, L. (2007) EBG-Embedded Multiple-Mode Resonator for UWB Bandpass Filter with Improved Upper Stop Band Performance. IEEE Microwave Wireless Component Letters, 17, 421-423. https://doi.org/10.1109/LMWC.2007.897788

[16] Zhu, L. (2003) Guided-Wave Characteristics of Periodic Coplanar Waveguides with Inductive Loading: Unit Length Transmission Parameters. IEEE Transactions on Microwave Theory and Techniques, 51, 2133-2138.

[17] Hong, J.-S. and Lancaster, M.J. (2000) Transmission Line Filters with Advanced Filtering Characteristics. 2000 IEEE MTT-S International Microwave Symposium 
Digest, Boston, MA, USA, 11-16 June 2000, 319-322.

[18] Pozar, D.M. (2010) Microwave Engineering. 3rd Edition, John Wiley, Hoboken, NJ.

[19] Tahanian, E., Chamaani, S. and Mirtaheri, S.A. (2010) Compact Ultra-Wideband Bandpass Filters Using EBG. Electronics Letters, 46, 1328-1330. https://doi.org/10.1049/el.2010.0257

[20] Jadhav, J. and Deore, P. (2016) A Compact Planar Ultra-Wideband Bandpass Filter Based on Multiple Resonant and Defected Ground Structure. Asia-Pacific Microwave Conference (APMC), Newdelhi, India, 5-9 December 2016, 1-3. https://doi.org/10.1109/APMC.2016.7931400

[21] Shan, Q., Chen, C. and Wu, W. (2016) Design of an UWB Bandpass Filter with a Notched Band Using Asymmetric Loading Stubs. IEEE International Conference on Microwave and Millimeter Wave Technology (ICMMT), Beijing, China, 5-8 June 2016, 410-412. https://doi.org/10.1109/ICMMT.2016.7761791

[22] Song, Y., Yang, G.M. and Geyi, W. (2014) Compact UWB Bandpass Filter with Dual Notched Bands Using Defected Ground Structures. IEEE Microwave and Wireless Components Letters, 2, 230-232.

https://doi.org/10.1109/LMWC.2013.2296291

[23] Zhu, H. and Chu, Q.X. (2013) Ultra-Wideband Bandpass Filter with a Notch-Band Using Stub-Loaded Ring Resonator. IEEE Microwave and Wireless Components Letters, 23, 341-343. https://doi.org/10.1109/LMWC.2013.2262928

[24] Federal Communication Committee (2002) First Report and Order, Revision of Part 15 Commission's Rule Regarding Ultra Wideband Transmission Systems. FCC $02-48$. 